prayed-for group actually did worse than the non-prayed-for group); the search for the soul in everything from stem cells and embryos to the 21-gram weight differential after death (needless to say no souls have been found, and the 21 grams was an artefact of the measuring techniques); the quest for the afterlife (on an ABC TV special, no less, with Barbara Walters interviewing actors and celebrities, experts all on the afterlife); the problem of evil, or why bad things happen to good people (why can't God prevent plate tectonics from causing earthquakes that destroy entire villages of his innocent creations?); New Age cures "they don't want you to know about", in which nostrums such as quantum physics will prevent ageing (then why does Deepak Chopra, author of The Quantum Alternative to Growing Old, look like he's getting old?); psychics (none have performed better than a coin-flip model of chance); alternative medicine (whatever you were doing just before you got better gets the credit for the healing, and as homeopathy does nothing and people still get better, it gets lots of credit); acupuncture (a good placebo for pain, but can't cure cancer or aids or anything else for that matter), and other claims of the weird and wonderful.

Superstition is more than an entertaining romp through the weird and wonderful. It is an important contribution to the sceptical literature on the latest claims of the preternatural and the paranormal that every scientist needs to be aware of when confronted by people honestly curious about what they should believe, and genuinely concerned about their future.

\section{Michael Shermer}

Michael Shermer is the Publisher of Skeptic magazine (www.skeptic.com), a monthly columnist for Scientific American, an adjunct professor at Claremont Graduate University, and the author of Why People Believe Weird Things.

\title{
EXHIBITION
}

\section{Drawn to the prize winners}

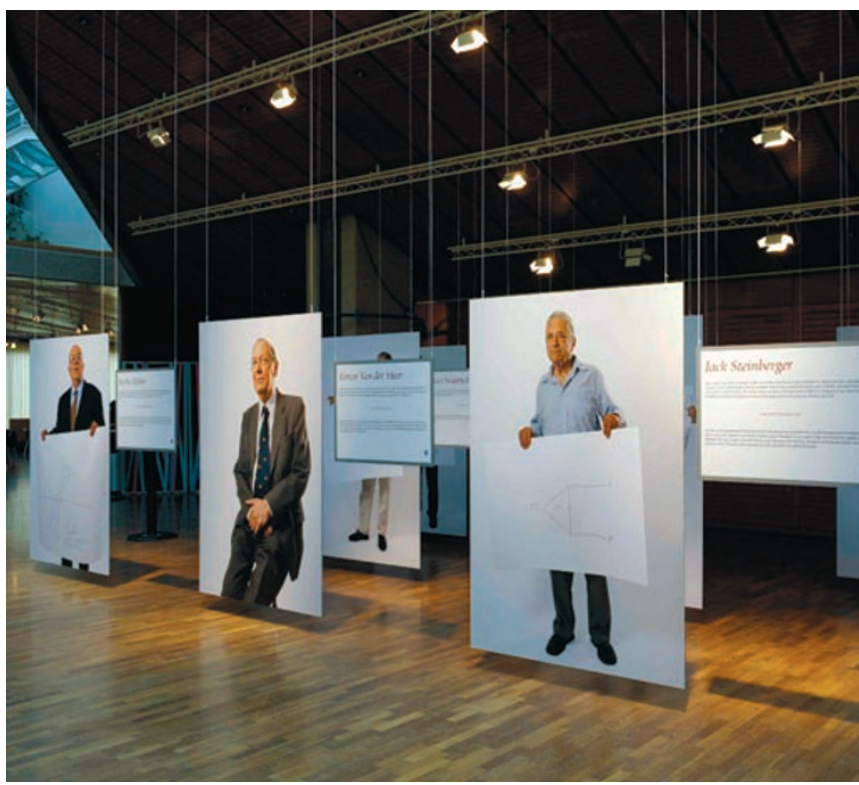

Each year, the announcement of the Nobel Prize generates a barrage of publicity. Those receiving the accolade - as this year's winners will no doubt agree - must get used to having their photo taken.

Over the past five years, science photographer Volker Steger has been revisiting past winners, to create a new set of portraits. Steger also supplied his subjects with coloured pencils and asked them to draw their discovery; each was then photographed with their drawing. The portraits now form the exhibition An Accelerator of Nobel Prize Winners inside the Globe of Science and Innovation at CERN, in Geneva.

Fittingly for an exhibition at CERN, several particle physicists feature among the prize winners. They include Jack Steinberger, who shared the Nobel in 1988 for his part in the discovery of the muon neutrino; and Simon van der Meer, whose invention of stochastic cooling made possible the proton-antiproton collisions in the SPS accelerator that resulted in the discovery of the $W$ and $Z$ bosons. (The SPS is now part of the injection system into the more powerful Large Hadron Collider, where there is also hope of discovering a boson...).

Sam Ting's artwork (seen in his portrait here) portrays his Nobelwinning discovery of the $J$ particle, made at Brookhaven National Laboratory in November 1974 - on the right is the unmissable peak in the spectrum of electron-positron pairs, coming from the decay of a particle whose mass is slightly higher than $3 \mathrm{GeV} \mathrm{c}{ }^{-2}$. Burton Richter (who also features in the exhibition) made the same find at the Stanford Linear Accelerator Centre at the same time, and called it the $\Psi$ particle. This bound state of charm and anticharm quarks has been known ever since as the $J / \Psi$, its discovery - the 'November revolution' in the folklore of particle physics - signalling the existence of a second generation of quarks.

The exhibition runs at CERN (www.cern.ch) until 11 October 2008.

\section{Alison Wright}

